\title{
Attitudes to fertility issues among adults with cystic fibrosis in Scotland
}

\author{
A Fair, K Griffiths, L M Osman, for the Collaborative Group of the Scottish Adult CF \\ Centres
}

\begin{abstract}
Background-With increasing life expectancy, issues of fertility and pregnancy are pertinent to patients with cystic fibrosis. For this reason, the four Scottish Cystic Fibrosis centres asked men and women with cystic fibrosis about their attitudes to fertility and to information given to them by health professionals.
\end{abstract}

Methods-A postal questionnaire was sent to 116 men and 79 women aged 16 years and over attending four Scottish Cystic Fibrosis clinics.

Results-There was a $70 \%$ response rate (82 men, 54 women). All but two men knew that they were likely to be infertile. $37 \%$ of respondents lived with a partner; 14 women $(26 \%)$ and five men $(6 \%)$ had children. For $85 \%$ of men and $72 \%$ of women having children was important now or would be in the next 10 years. $43 \%$ of men and $26 \%$ of women had never had any discussion on fertility issues with cystic fibrosis health professionals. $56 \%$ of men thought that first discussion with a health professional about infertility should be before the age of 16 years; $12 \%$ remembered having a first discussion at that age. Learning of their infertility was associated with strong negative emotions for most men. Women were more likely than men to have initiated first discussion $(17(32 \%)$ versus eight $(10 \%) ; p<0.01)$. Twenty five men (31\%) and 32 women $(59 \%)$ were currently using contraception. Ten men $(12 \%)$ and 15 women $(28 \%)$ had discussed contraception at the Cystic Fibrosis clinic $(\mathbf{p}=\mathbf{0 . 0 1})$.

Conclusions-Parenting and fertility issues are important for men and women with cystic fibrosis but many patients do not find out what they want to know from discussion with health professionals. Patients want discussion to begin in early adolescence. Men in particular are likely to be reluctant to introduce these issues; health professionals should be aware of the need actively to initiate discussion.

(Thorax 2000;55:672-677)

Keywords: cystic fibrosis; fertility; communication

It is estimated that there are 2700 people aged over 16 with cystic fibrosis in the UK. ${ }^{1}$ Children born with cystic fibrosis in 1990 are estimated to have a life expectancy of 40 years, double that of 20 years ago. ${ }^{2}$ This increase in the population of adults with cystic fibrosis means that they will need information on sexuality and fertility.

Fertility is a particularly sensitive and important issue in cystic fibrosis because more than $95 \%$ of male sufferers are infertile. ${ }^{3}$ Although infertile, sexual function is not usually affected by cystic fibrosis. ${ }^{4}$ Women with cystic fibrosis may have reduced fertility ${ }^{5}$ and pregnancy may put their health at risk. ${ }^{6}$ Because of this, pregnancy in women with cystic fibrosis should be planned and discussed with the relevant team. ${ }^{3}$

Studies suggest that not all subjects with cystic fibrosis understand how this affects their reproductive capacity. In a previous study in the UK only $27 \%$ of men and women with cystic fibrosis knew how the reproductive organs are affected. ${ }^{7}$ In another study Conway et $a l^{8}$ found that 10 out of 37 men thought that men with cystic fibrosis were not infertile. In contrast, an Australian study by Sawyer et al found that $90 \%$ of men over 17 years knew they were infertile.

An unpublished study by Thicket et al in 72 men with cystic fibrosis attending the Birmingham Adult Cystic Fibrosis Unit found that $88 \%$ were sexually active but $56 \%$ had never received advice on contraception and infertility. Fifty seven percent were aware that it is rare for men with cystic fibrosis to father children, but $68 \%$ expressed a wish to have children. Shepherd et $a l^{10}$ found that men and women with cystic fibrosis were as likely to be married or in a sexual relationship as a non-cystic fibrosis matched control group.

Sawyer et $a l^{9}$ found that $83 \%$ of $14-17$ year old boys said that being infertile was not significant while only $10 \%$ of men over 17 regarded their infertility as insignificant. They suggest that the significance of infertility changes with age, and that the issue should be introduced at around the age of 14 years and returned to in later reviews. Hames et al found that patients under 13 wanted to receive information from both their parents and clinical staff, while those aged over 13 preferred that health care providers supplied them with information. Johannesson et $a l^{11}$ found that adult Danish women with cystic fibrosis thought that 13-14 years was the best time to introduce discussion about sexuality. Few women felt they had had satisfactory discussions. It was concluded that feelings such as denial, anger, and grief about fertility decisions were present among the women interviewed. Glover et $a l^{12}$ found that men not suffering from cystic fibrosis who attended a specialist male subfertility clinic felt "less of a man", had high levels of 
anxiety, and blamed themselves for their infertility. Sawyer et al found similar negative feelings among men with cystic fibrosis. ${ }^{9}$

The four Scottish adult Cystic Fibrosis clinics (based in Aberdeen, Dundee, Edinburgh and Glasgow) felt it would be of value to carry out a study investigating fertility issues. The aims of the study were (1) to determine attitudes about fertility and pregnancy among subjects with cystic fibrosis aged 16 years and over attending the clinics and (2) to determine satisfaction with communication on this issue from health professionals.

\section{Methods}

POPULATION

The study population comprised 116 men and 79 women from the four Scottish Cystic Fibrosis clinics aged 16 years and over. In Scotland transfer to an adult Cystic Fibrosis clinic usually takes place at the age of 14 . Twenty men and three women were excluded from the study at the discretion of their consultant.

\section{QUESTIONNAIRE}

A questionnaire was developed by nurses from all the centres, psychologists (two centres), consultants (all centres), and representatives of the National Services Division, NHS. It was piloted on eight adult patients from the centres, four men and four women. From the results of the pilot study an amended questionnaire was finalised. Approval for the study was obtained from the ethics committee of each participating centre.

\section{QUESTIONNAIRE CONTENT}

The male questionnaire dealt with discussion about infertility while the female questionnaire focused on the issue of pregnancy for women with cystic fibrosis. Some questions were identical for men and women such as "Do you live with a partner?", "How do you feel if a health professional questions whether or not you should have a child?", "Has (male infertility)/ (fertility or pregnancy) in cystic fibrosis ever been discussed with you by a health professional?", "Have you been able to find out all you want to know during these discussions?". Questions in the male questionnaire that had no equivalent in the female questionnaire asked if the respondent was aware that men with cystic fibrosis were usually infertile, at what age they had learnt this, from whom, and what they had felt about their probable infertility.

CLINICAL DATA

For all patients surveyed, participating centres provided the most recent percentage predicted forced expiratory volume in one second $\left(\mathrm{FEV}_{1}\right)$ for age, sex and height, and body mass index (BMI).

ANALYSIS OF DATA

SPSS-PC was used to store and analyse quantitative data. Two tailed Student's $t$ tests were used to test for significant differences between subgroups for parametric data and Mann-
Table 1 Patient characteristics

\begin{tabular}{|c|c|c|}
\hline & $\operatorname{Men}(n=82)$ & Women $(n=54)$ \\
\hline Age (years) ${ }^{\star}$ & $24.5(20-31)$ & $24.0(19-31)$ \\
\hline Age at diagnosis (years) & $1.3(<1-12.3)$ & $2(<1-10)$ \\
\hline $\mathrm{FEV}_{1}(\% \text { predicted })^{\star}$ & $52.6(32.3-72.6)$ & $59.9(44.5-75.5)$ \\
\hline $\operatorname{BMI}\left(\mathrm{kg} / \mathrm{m}^{2}\right)^{\star}$ & $20.1(18.5-22.6)$ & $21.0(19.1-23.1)$ \\
\hline Employed & $39(48 \%)$ & $26(48 \%)$ \\
\hline Studying & $16(20 \%)$ & $10(19 \%)$ \\
\hline Married/living with partner & $30(37 \%)$ & $20(37 \%)$ \\
\hline One or more childrent & $5(6 \%)$ & $14(26 \%)$ \\
\hline
\end{tabular}

$\mathrm{FEV}_{1}=$ forced expiratory volume in one second; $\mathrm{BMI}=$ body mass index.

$\star$ Values are median (interquartile range).

†Five men with children four had successfully taken part in an assisted fertility programme.

Whitney $U$ tests and $\chi^{2}$ tests were used for non-parametric data. The NUD*ist package was used to classify open ended, qualitative responses.

\section{Results}

EXCLUSIONS

Twenty three patients were excluded from the study, mainly for social reasons-for example, being in prison or a request by the mother of a patient that he be excluded. It was thought possible that three of the excluded men did not know of male infertility. Excluded patients did not differ in mean age (24 years versus 26 years, $p=0.13$ ), but they had better mean $\mathrm{FEV}_{1}(63 \%$ versus $55 \%$ predicted, $\mathrm{p}<0.05)$.

Of the 195 patients sent a questionnaire 136 (70\%) responded (82 men and 54 women). There were no differences between respondents and non-respondents in sex, mean age (25 years versus 26 years), or mean $\mathrm{FEV}_{1}(56 \%$ versus $51 \%$ predicted, $\mathrm{p}=0.10$ ).

\section{PATIENT CHARACTERISTICS}

The characteristics of the 136 patients who participated in the study are shown in table 1 . Their median age was 24 years and most had been diagnosed in early childhood. Median $\mathrm{FEV}_{1}$ was $53 \%$ for men and $60 \%$ predicted for women. Thirty nine men (48\%) and 26 women (48\%) were in employment.

\section{LEARNING OF INFERTILITY: MEN}

All but two men said they were aware that men with cystic fibrosis are usually infertile. Neither of these men lived with a partner or had children. Twenty nine men (37\%) learnt that they were infertile before the age of 16 and $20 \%$ between 16 and 19 . Twenty one $(26 \%)$ were over 20 years and 15 did not answer the question or could not remember. Thirty four men $(41 \%)$ had found out about their infertility from the Cystic Fibrosis clinic, 21 (26\%) from their parents, and 16 (20\%) from Cystic Fibrosis Trust leaflets. Learning from parents was usually before 16 years $(67 \%, p<0.01)$, learning from the clinic was after 20 years $(62 \%, \mathrm{p}<0.01)$, and learning from literature was most common between 16 and 19 years $(50 \%, \mathrm{p}<0.01)$.

When men were asked how they felt when told of their infertility, the most common replies were "shocked" (33, 40\%), "bewildered" (19, 24\%) and "angry" (15, 19\%). 
Table 2 Attitudes to parenting and fertility

\begin{tabular}{|c|c|c|c|}
\hline & $\begin{array}{l}\text { Men } \\
(n=82)\end{array}$ & $\begin{array}{l}\text { Women } \\
(n=54)\end{array}$ & $p$ value \\
\hline \multicolumn{4}{|c|}{$\begin{array}{l}\text { "How important is having children to you at } \\
\text { present or in the next } 10 \text { years?" }\end{array}$} \\
\hline Not at all important & $12(15 \%)$ & $15(28 \%)$ & \\
\hline Quite/very important & $70(85 \%)$ & $39(72 \%)$ & 0.05 \\
\hline \multicolumn{4}{|c|}{$\begin{array}{l}\text { "Do you worry that if you had a child it may have } \\
\text { cystic fibrosis?" }\end{array}$} \\
\hline Yes & $48(59 \%)$ & $30(56 \%)$ & \\
\hline No & $18(22 \%)$ & $13(26 \%)$ & NS \\
\hline Never think about it/NA & $16(19 \%)$ & $11(18 \%)$ & \\
\hline \multicolumn{4}{|c|}{$\begin{array}{l}\text { "How do you feel if a health professional questions } \\
\text { if you should have a child?" }\end{array}$} \\
\hline Shocked & $12(15 \%)$ & $9(17 \%)$ & NS \\
\hline Angry & $25(31 \%)$ & $20(37) \%$ & NS \\
\hline Relieved & $6(7 \%)$ & $0 \%$ & $<0.05$ \\
\hline Resigned & $8(10 \%)$ & $6(11 \%)$ & NS \\
\hline Not bothered & $26(32 \%)$ & $19(35 \%)$ & NS \\
\hline
\end{tabular}

Nineteen men (24\%) reported feeling "not bothered". Only one reported feeling "relieved or pleased" (table 2).

MEN'S EXPERIENCE OF ASSISTED FERTILITY PROGRAMMES

Thirty men said they had some knowledge of assisted fertility programmes. Four had successfully had a child through assisted fertility and two had been unsuccessful in a programme.

HAVING A FAMILY: MEN AND WOMEN

Thirty men (37\%) and 20 women $(37 \%)$ were married or living with a partner. Fourteen women $(26 \%)$ had children and five men $(6 \%)$ described themselves as having children (four through an assisted fertility programme) (table $1)$. Men and women who were married or living with a partner were older (mean age 31 versus 23 years, $\mathrm{p}<0.001$ ) but had similar mean $\mathrm{FEV}_{1}(57 \%$ versus $55 \%$ predicted, NS) to those not living with a partner. Men and women with children were older than those without ( 33 versus 25 years, $\mathrm{p}<0.001$ ) and had higher $\mathrm{FEV}_{1}(68.1 \%$ versus $53.7 \%$ predicted, $\mathrm{p}<0.01$ ).

Most respondents described having children as being important either now or in the future (table 2). More than half worried that, if they had a child, it would have cystic fibrosis. One in three respondents would be angry if a health professional questioned whether they should have a child (table 2 ; box 1 ). Among those who did not have children at present, respondents who thought having children now or in the next 10 years was important did not differ in lung function from those who did not think having children was important (mean $\mathrm{FEV}_{1}$ (53\% versus $58 \%$ predicted, NS).

CONTRACEPTION: MEN AND WOMEN

Twenty five men (31\%) and 32 women (59\%) were using some form of contraception (condom for men; pill or IUD for women). Ten men $(12 \%)$ and 15 women $(28 \%)(p<0.05)$ had discussed contraception at a Cystic Fibrosis clinic (table 3).

DISCUSSION WITH A HEALTH PROFESSIONAL: MEN AND WOMEN

Women were more likely than men to have discussed fertility with a health professional ( $74 \%$
Talking to health professionals

"I have never had the courage to bring up the subject" (M, 26 years, $\mathrm{FEV}_{1} 65 \%$

predicted).

"I would welcome an honest opinion because I wouldn't want to make the wrong decision" (F, 19 years, $\mathrm{FEV}_{1} 53 \%$ predicted).

"When I was pregnant with my second the doctor at the maternity said to me 'Who gave you permission to have another child?"' (F, 41 years, $\mathrm{FEV}_{1} 47 \%$ predicted).

(The doctor said to me) "I hope you're not going to get pregnant because if you do it will kill you" (F, 20 years, $\mathrm{FEV}_{1} 20 \%$

predicted).

"How would you feel if a health
professional questions if you should
have a child?"
"I would be very angry because you are a
normal woman and if in a relationship both
you and your partner feel the same as any
young couple and having a family may feel
like the next step" (F, 32 years FEV $58 \%$
predicted).
"I think this would be beneficial, but sad if
he/she tells you it's best not to have a child. It is
best if they tell you the exact truth" (F, 17
years, FEV $66 \%$ predicted).
"It's up to the individual, nothing to do with
anyone else" (M, 25 years, FEV $43 \%$
predicted).

Box 1 Discussion about fertility.

versus $57 \%, \mathrm{p}<0.05$; table 3 ). Women were more likely than men to start the first discussion ( $32 \%$ versus $10 \%, \mathrm{p}<0.01$ ). Twelve men $(15 \%)$ and 12 women $(24 \%)$ said they had been able to find out all they wanted to know from discussions with a health professional. Fifty eight per cent of men and women wanted written information about fertility issues, pregnancy, or screening. Less than a quarter (18 men $(24 \%)$ and seven women (14\%)) remembered receiving any.

AGE AND PERSON FOR FIRST DISCUSSION: MEN AND WOMEN

Table 3 shows that, although few men had their first discussion with a health professional about infertility before the age of 16, this was men's preferred age for first discussion (46, 57\%). Women suggested 16-19 years (25, 46\%). Eighteen women (34\%) had had a first discussion at this age. Only nine men $(11 \%)$ and nine women $(17 \%)$ thought first discussion should be at over 20 years. Most men $(69,84 \%)$ and women $(37,69 \%)$ said they had no preference for discussion with someone of the same sex, but when asked which health professional they would prefer, men preferred to discuss with a doctor $(46,56 \%)$ and women preferred a cystic fibrosis nurse $(38,70 \%)$.

OPEN ENDED COMMENTS

Thirty men $(37 \%)$ and 38 women $(70 \%)$ gave comments to open ended questions. The 24 
Table 3 Discussion with health professional about infertility, pregnancy and contraception

\begin{tabular}{|c|c|c|c|}
\hline & $\begin{array}{l}\text { Men } \\
(n=82)\end{array}$ & $\begin{array}{l}\text { Women } \\
(n=54)\end{array}$ & $p$ value \\
\hline \multicolumn{4}{|c|}{$\begin{array}{l}\text { "Has male infertility/female fertility/pregnancy ever been } \\
\text { discussed with you by a health professional?" }\end{array}$} \\
\hline Yes & $47(57 \%)$ & $40(74 \%)$ & \\
\hline No/NA & $35(43 \%)$ & $14(26 \%)$ & $<0.05$ \\
\hline \multicolumn{4}{|c|}{ "Did you start this discussion?" } \\
\hline Yes & $8(10 \%)$ & $17(32 \%)$ & $<0.01$ \\
\hline No/NA & $74(90 \%)$ & $37(68 \%)$ & \\
\hline \multicolumn{4}{|c|}{ "Have you found out all you want to know in these discussions?" } \\
\hline Yes & $12(15 \%)$ & $12(22 \%)$ & \\
\hline To some extent & $29(35 \%)$ & $32(41 \%)$ & NS \\
\hline No/No discussion & $41(50 \%)$ & $20(37 \%)$ & \\
\hline \multicolumn{4}{|c|}{ Age of first discussion with health professional } \\
\hline$<16$ years & $9(12 \%)$ & $3(6 \%)$ & \\
\hline $16-19$ years & $16(20 \%)$ & $18(34 \%)$ & \\
\hline $20-24$ years & $6(8 \%)$ & $11(21 \%)$ & $<0.05$ \\
\hline 25 years and older & $16(20 \%)$ & $6(12 \%)$ & \\
\hline Never had discussion & $35(40 \%)$ & $16(27 \%)$ & \\
\hline \multicolumn{4}{|c|}{ Preferred age of first discussion with health professional } \\
\hline$<16$ years & $46(56 \%)$ & $17(32 \%)$ & \\
\hline $16-19$ years & $27(33 \%)$ & $25(46 \%)$ & \\
\hline $20-24$ years & $9(11 \%)$ & $9(16 \%)$ & $<0.05$ \\
\hline 25 years and older & - & - & \\
\hline NA & - & $3(6 \%)$ & \\
\hline \multicolumn{4}{|c|}{ "Do you use any form of contraception at present?" } \\
\hline Yes & $25(31 \%)$ & $32(59 \%)$ & \\
\hline $\mathrm{No} / \mathrm{NA}$ & $57(69 \%)$ & $22(41 \%)$ & $<0.01$ \\
\hline \multicolumn{4}{|c|}{ "Have you discussed contraception at the clinic?" } \\
\hline Yes & $10(12 \%)$ & $15(28 \%)$ & \\
\hline $\mathrm{No} / \mathrm{NA}$ & $72(88 \%)$ & $39(72 \%)$ & $<0.05$ \\
\hline
\end{tabular}

men aged 20 years or less were particularly unlikely to answer open ended questions (6, $25 \%)$.

TALKING TO HEALTH PROFESSIONALS

In an open ended question men and women were asked to comment on talking to health professionals about fertility and to comment on how they would feel if a health professional questioned if they should have a child. Some examples of comments are shown in box 1 .

WHAT SORT OF INFORMATION?

Box 2 shows examples of comments on the kind of information wanted. Women gave a detailed and rich commentary on the information they thought should be given. Three themes emerged from female responses: (1) wanting more information about health consequences of pregnancy, (2) suggesting information to give to other women, particularly about the long term health effects from pregnancy; and (3) describing satisfactory and unsatisfactory discussion with cystic fibrosis doctors and nurses.

Men made few specific suggestions about what information they wanted and seemed to divide into those who wanted "the facts" and those who wanted the emotional impact of infertility to be recognised by their health professionals. Most men did not seem to be aware of the relatively low success rate of assisted fertility treatment. Of 30 comments from men, nine were on the positive chance that they would be able to have children through assisted fertility and no man commented on the low success rate of fertility programmes. As noted previously, men aged 20 years and under were much less likely than women or older men to make any comment on what information they wanted. Older men with good lung function seemed most likely to be distressed by their infertility (box 2).

\section{Women}

"(explain that) you will feel ill during and maybe for years after giving birth and when you have your baby, there's almost no time to be unwell yourself which can cause problems"

( $\mathrm{F}, 23$ years, $\mathrm{FEV}_{1} 44 \%$ predicted).

"Information about general health during pregnancy and risks about the actual birth"

(F, 16 years, $\mathrm{FEV}_{1} 50 \%$ predicted).

"To let them know that 14 days of IVS will be administered at home after the birth of the baby" (F, 29 years, $\mathrm{FEV}_{1} 60 \%$ predicted). "I felt no one would help me at least try and come to a decision. I had so little information. I was constantly told the risks were too high and now it's too late and I feel there's a huge gap in my life" ( $\mathrm{F}, 33$ years, $\mathrm{FEV}_{1} 62 \%$ predicted).

\section{Men}

"Simple cans and can'ts, facts ... to the point, no 'maybe you can but ... etc'." (M, 20 years)

"I do feel this can be a very emotional issue"

(M, 23 years, $\mathrm{FEV}_{1} 45 \%$ predicted).

"Facts as they stand with hope via assisted fertility information" (M, 28 years, $\mathrm{FEV}_{1}$ $22 \%$ predicted).

"I feel that there should be discussions and literature handed out in CF Clinic at an earlier stage e.g. not later than 16" (M, 20 years, $\mathrm{FEV}_{1} 65 \%$ predicted).

"Make sure he knows about it early so he can learn to accept it easier" (M, 27 years, $\mathrm{FEV}_{1}$ $40 \%$ predicted).

Older men with good lung function "I would like more information on how other people are handling the fact that they cannot have children" (M, 35 years, $\mathrm{FEV}_{1} 84 \%$ predicted).

"Give some hope of being able to father and try and make them not feel a failure if they can't father children" (M, 31 years, $\mathrm{FEV}_{1}$ $96 \%$ predicted).

"It is terrifying for men not to be able to father a child" (M, 34 years, $\mathrm{FEV}_{1} 84 \%$

predicted).

\section{Box 2 What sort of information?}

\section{Discussion}

These results show that having children is important to most men and women with cystic fibrosis, but only a few men and women felt they had been able to have an adequate discussion with a health professional about fertility.

Among the respondents, all but two men knew they were probably infertile (another three excluded men may not have known). This is similar to the study by Sawyer et $a l^{9}$ in which $90 \%$ of adult men knew they were infertile. Patients who learnt through the Cystic Fibrosis clinic were older than patients who learnt from their parents. This suggests that the topic has commonly not been dealt with by health professionals during adolescence.

Although women seem more able to introduce discussion of fertility issues than men, women often did not feel that they were given adequate information. Contraception, reproductive health, and timing of pregnancy are all 
issues on which women with cystic fibrosis need advice in order to be able to make informed decisions. In the present study $22 \%$ of women had been able to find out what they wanted to know from discussions with health professionals; $59 \%$ were using contraception (compared to national UK rates of $65 \%{ }^{13}$ ) and half of these had discussed contraception at their Cystic Fibrosis clinic. Few men $(12 \%)$ reported any discussion of contraception in the clinic in spite of its importance for avoiding risk of sexually transmitted disease and thrush.

It is possible that these results do have some distortion from incorrect recall and they reflect practice over the person's 20 years of care. However, the preferences of our respondents were clear. The patients' judgement, looking back on their experience, was that fertility issues should be introduced by health professionals during adolescence. Sawyer et $a l^{14}$ found among 40 men aged 18-53 years that the median age at which patients thought it appropriate to learn about infertility was 14 years; the median age at which the respondents had learnt was 16 years. Similarly, in our study $56 \%$ of men think that $12-15$ is the best age to discuss infertility but only $12 \%$ remembered having a discussion at that age. However, men did not give us a clear picture of what information they thought should be given at this age. Infertility obviously aroused strong negative feelings in many of our respondents; $20 \%$ of the respondents in the study by Sawyer et $a l^{14}$ confused infertility with impotence. Puberty is delayed in many young men with cystic fibrosis and Sinnema et $a l^{15}$ found that intimacy and sexual relationships were delayed among boys and girls with cystic fibrosis in comparison with a noncystic fibrosis control group. Men with cystic fibrosis are likely to have small volume ejaculates. ${ }^{15}$ It is possible that the issue of "being normal" is what boys want addressed at early puberty.

Men said that they would prefer to discuss infertility with a doctor but women preferred to discuss pregnancy with a cystic fibrosis nurse. It was not clear why this was so. Although most denied this when explicitly questioned, people with cystic fibrosis may prefer to discuss these issues with their own sex and their expectation may be that most doctors are men and nurses are women.

EMOTIONS AND ADVICE ON FERTILITY

Sawyer et $\mathrm{al}^{14}$ believed that there was little evidence of negative emotion associated with learning of infertility, but two thirds of men in this survey reported feeling negative emotions such as shock and bewilderment when told that they were infertile. Between $30 \%$ and $40 \%$ of men and women said they would feel angry if a health professional questioned whether they should have a child. Genetic screening advice is a sensitive area even when it is not associated with personal health concerns. Sawyer ${ }^{6}$ found that many women overestimated the risk of having a child with cystic fibrosis. Almost two thirds of men and women in the present study were worried that, if they had a child, it too would have cystic fibrosis. Previous studies have shown the adverse psychological effect of knowledge about carrier status. ${ }^{17}$ Health professionals may underestimate the emotional impact of genetic information.

In conclusion, this study and previous studies $^{6}{ }^{18}$ indicate that discussion should start in early adolescence. The content of discussion will change as patients mature, particularly for men. A 14 year old boy probably needs the basic facts of his infertility, with reassurance that his development will be normal and that infertility does not affect sexuality. A 25 year old might want detailed information about infertility treatments. Women of all ages want advice on reproductive health, and the health implications and possibilities for pregnancy. Men and women will be concerned about genetic issues when they begin long term relationships and consider decisions about parenting. In this survey patients in their late twenties were likely to be living with a partner and to place importance on having children.

Having better or worse lung function was not significantly related to the likelihood of living with a partner, using contraception, or placing importance on having children, although the open ended comments suggested that older men with good lung function found it more difficult to come to terms with infertility.

It is the responsibility of Cystic Fibrosis centres to offer information on fertility to patients with during adolescence and, in the case of women, to discuss with individual patients the potential impact of pregnancy on cystic fibrosis. Patients can then make informed choices. The onus is on health professionals to instigate discussion about fertility because it appears that people find it a difficult subject to bring up themselves.

Collaborative Group of the Scottish Adult CF Centres: S Hempsey, Gartnaval Hospital, Glasgow; K Liddle, Western General Hospital, Edinburgh; M Pogson, Ninewells Hospital, Dundee; J Young, Gartnaval Hospital, Glasgow; B H R Stack, Gartnaval Hospital, Glasgow; J A R Friend, Aberdeen Royal Infirmary Aberdeen; A Greening, Western General Hospital Infirmary, Aberdeen; A Greening, Western General The aim of the study was formulated by the CF Working
The Group. L M Osman and K Griffiths supervised the study and, with the Working Group, were responsible for the design. A Fair carried out the study and wrote the first draft of this paper in conjunction with $\mathrm{L} M$ Osman and K Griffiths. The final draft was completed by L M Osman and K Griffiths. L M Osman and A Fair were responsible for the analysis.

The authors would like to thank all the patients who gave their time in answering the questionnaires and also acknowledge the assistance of L Howells, K Collins, L Smith, J S Legge, J A Innes, J Winter, J Fiddes and I Yackiminie.

Funding: The study was funded by the National Services Division, NHS, Scotland.

1 Dodge JA, Morison S, Lewis PA, et al. Incidence, population, and survival of cystic fibrosis in the UK, 19685. UK Cystic Fibrosis Survey Management Committee. Arch Dis Child 1997;77:493-6.

2 Elborn JS, Shale DJ, Britton JR. Cystic fibrosis: current survival and population estimates to the year 2000. Thorax 1991;46:881-5

3 Kotloff RM, FitzSimmons SC, Fiel SB. Fertility and pregnancy in patients with cystic fibrosis. Clin Chest Med 1992;13:623-35.

4 Oates RD, Amos JA. Congenital bilateral absence of the vas deferens and cystic fibrosis. A genetic commonality. World $\mathcal{F}$ Urol 1993;11:82-8.

5 Frangolias DD, Nakielna EM, Wilcox PG. Pregnancy and cystic fibrosis: a case-controlled study. Chest 1997;111: cystic 96.

6 Sawyer SM. Reproductive and sexual health in adolescents with cystic fibrosis. BMF 1996;313:1095-6. 
7 Hames A, Beesley J, Nelson R. Cystic fibrosis: what do patients know, and what else would they like to know? (1)

8 Conway SP, Pond MN, Hamnett T, et al. Compliance with treatment in adult patients with cystic fibrosis. Thorax 1996;51:29-33.

9 Sawyer SM, Tully MA, Dovey ME, et al. Reproductive health in males with cystic fibrosis: knowledge, attitudes, and experiences of patients and parents. Pediatr Pulmonol 1998;25:226-30.

10 Shepherd SL, Hovell MF, Harwood IR, et al. A comparative study of the psychosocial assets of adults with cystic fibrosis and their healthy peers. Chest 1990;97:1310-6.

11 Johannesson $M$, Carlson $M$, Brucefors AB, et al. Cystic fibrosis through a female perspective: psychosocial issues and information concerning puberty and motherhood. Patient Education E Counseling 1998;34:115-23.

12 Glover L, Gannon K, Abel PD. Distress in subfertile men: a longitudinal study. F Reprod Infant Psychol 1996;14:23-36.
13 United Nations Population Information Network (POPIN). United Kingdom: socio-demographic profile. International Planned Parenthood Federation, 2000.

4 Sawyer SM. Reproductive health in young people with cystic fibrosis. Curr Opin Pediatr 1995;7:376-80.

15 Sinnema G, Bonarius HC, Van der Laag H, et al. The development of independence in adolescents with cystic fibrosis. f Adolescent Health Care 1988;9:61-6.

16 Denning CR, Sommers SC, Quigley HJ Jr. Infertility in male patients with cystic fibrosis. Pediatrics 1968;41: $7-17$

17 Axworthy D, Brock DJ, Bobrow M, et al. Psychological impact of population-based carrier testing for cystic fibrosis: three-year follow-up. UK Cystic Fibrosis Follow-Up Study Group. Lancet 1996;347:1443-6.

18 Sawyer SM, Phelan PD, Bowes G. Reproductive health in young women with cystic fibrosis: knowledge, behavior and attitudes. F Adolescent Health 1995;17:46-50. 